\title{
Nesiritide: Harmful or Harmless?
}

\author{
Michael P. Dorsch, Pharm.D., and Jo Ellen Rodgers, Pharm.D.
}

Nesiritide is the recombinant form of human B-type (brain) natriuretic peptide (BNP), and its amino acid sequence is identical to that of endogenous human BNP. Administration of nesiritide results in venous and arterial vasodilation, as well as enhanced diuresis. Given the many limitations of therapies previously available for the treatment of acute decompensated heart failure, the anticipation was that nesiritide would offer a safer and more effective therapeutic option. Recently, two meta-analyses raised the question of safety with nesiritide therapy, specifically an increased risk of renal dysfunction and mortality. Although several studies generated information regarding the potential role of nesiritide in various settings, the questions raised by the meta-analyses are concerning. Our hope is that future clinical trials will address the concerns raised and provide a better understanding of the role of nesiritide in the management of acute decompensated heart failure. Until these data are available, nesiritide use should be limited.

Key Words: nesiritide, acute decompensated heart failure, vasodilator therapy. (Pharmacotherapy 2006;26(10):1465-1478)

\section{OUTLINE}

Limitations of Standard Therapies

Nesiritide Overview

Recent Controversial Literature

Nesiritide's Effect on Renal Function

Nesiritide's Effect on Mortality

Evolving Literature

Outpatient Setting

Emergency Department or Observational Unit

Reducing Length of Stay and Cost

Discussion

Conclusion

In the United States, 5 million people currently have heart failure, with 550,000 new cases diagnosed each year. This disease causes considerable morbidity and mortality and is responsible

From the Department of Pharmacy Services, University of Michigan Hospitals and Health Clinics, Ann Arbor, Michigan (Dr. Dorsch); and the University of North Carolina School of Pharmacy, University of North Carolina, Chapel Hill, North Carolina (Dr. Rodgers).

Dr. Rodgers is a consultant and on the speaker's bureau for Scios, Inc., Fremont, California.

Address reprint requests to Michael P. Dorsch, Pharm.D., BCPS, University of Michigan Hospitals and Health Clinics, Department of Pharmacy Services, UH B2D 301/0008, 1500 East Medical Center Drive, Ann Arbor, MI 48109-0008; email: mdorsch@med.umich.edu. for a tremendous burden on the health care system. The 1-year mortality rate is high, with one in five patients dying. In 2003, heart failure was responsible for more than one million hospital discharges, an increase of $174 \%$ over the previous two decades. The indirect and direct cost of managing this disease state in 2006 is estimated to be $\$ 29.6$ billion. ${ }^{1}$ Inpatient management of acute decompensated heart failure (ADHF) consumes the greatest expenditure for heart failure care and is associated with an increased risk of both readmission and subsequent death. $^{2}$

The goals of managing ADHF are different from those of chronic heart failure, such as prolonging survival, slowing disease progression, reducing hospitalization, and improving symptoms and quality of life. The goals of inpatient heart failure care include relieving pulmonary congestion, decreasing systemic vascular resistance, and improving myocardial systolic and diastolic function while preserving systemic perfusion pressure and optimizing oral drug therapy.

\section{Limitations of Standard Therapies}

Only limited guidance is available for 
Table 1. Results of the Pivotal Randomized, Controlled, Double-Blind Trials of Nesiritide 14-16 $^{14}$

\begin{tabular}{|c|c|c|c|c|}
\hline Trial & $\begin{array}{c}\text { No. of } \\
\text { Patients }\end{array}$ & $\begin{array}{l}\text { Control } \\
\text { Therapy }\end{array}$ & $\begin{array}{l}\text { Nesiritide Dosage } \\
\text { (bolus, infusion) }\end{array}$ & Primary End Point \\
\hline \multicolumn{5}{|l|}{$\mathrm{NSG}^{14}$} \\
\hline Efficacy & 127 & Placebo & $\begin{array}{r}0.3-\mu \mathrm{g} \text { bolus }+0.015 \mu \mathrm{g} / \mathrm{kg} / \mathrm{min} \\
0.6-\mu \mathrm{g} \text { bolus }+0.03 \mu \mathrm{g} / \mathrm{kg} / \mathrm{min}\end{array}$ & PCWP at 6 hrs \\
\hline Comparative & 305 & Standard ${ }^{a}$ & $\begin{array}{l}0.3-\mu \mathrm{g} \text { bolus }+0.015 \mu \mathrm{g} / \mathrm{kg} / \mathrm{min} \\
0.6-\mu \mathrm{g} \text { bolus }+0.03 \mu \mathrm{g} / \mathrm{kg} / \mathrm{min}\end{array}$ & $\begin{array}{l}\text { GCS } \\
\text { Clinical symptoms } \\
\text { (at } 6 \text { hrs, } 24 \text { hrs, and end of } \\
\text { therapy) }\end{array}$ \\
\hline VMAC $^{15}$ & 498 & $\begin{array}{l}\text { Placebo }^{\mathrm{b}} \\
\text { Nitroglycerin }^{-}\end{array}$ & $\begin{array}{l}2.0-\mu \mathrm{g} \text { bolus }+0.01 \mu \mathrm{g} / \mathrm{kg} / \mathrm{min} \times 3 \mathrm{hrs} \\
\text { then fixed dose vs adjustable dose } \\
\text { up to } 0.03 \mu \mathrm{g} / \mathrm{kg} / \mathrm{min}\end{array}$ & $\begin{array}{l}\text { PCWP and dyspnea at } 3 \text { hrs } \\
\text { (only compared with placebo) }\end{array}$ \\
\hline PRECEDENT ${ }^{16}$ & 255 & Dobutamine & $0.015,0.03 \mu \mathrm{g} / \mathrm{kg} / \mathrm{min}$ (no bolus) & $\begin{array}{l}\text { Changes from baseline to } 24 \mathrm{hrs} \text { : } \\
\text { Mean heart rate } \\
\text { Mean PVBs/hr } \\
\text { Mean repetitive beats/hr }\end{array}$ \\
\hline
\end{tabular}

$\downarrow$ = decreased; $\uparrow$ = increased; PCWP = pulmonary capillary wedge pressure; GCS = global clinical status; NS = not significant; NSG = Nesiritide Study Group; VMAC = Vasodilation in the Management of Acute CHF; PRECEDENT = Prospective Randomized Evaluation of Cardiac Ectopy with Dobutamine or Natrecor Therapy; PVBs = premature ventricular beats.

a Standard therapy is dobutamine (57\%), milrinone (19\%), nitroglycerin (18\%), dopamine (6\%), and amrinone (1\%).

blacebo for first $3 \mathrm{hrs}$ then randomized again to nesiritide or nitroglycerin.

practitioners who manage ADHF, with little consensus on definitions for physiologic and clinical disease state parameters, and current guidelines only briefly address management of this patient population. ${ }^{3}$ Until recently, the inpatient management of ADHF was also limited by the lack of supporting literature and the lack of development of more sophisticated therapies. For decades, intravenous loop diuretics and inotropes have been used as the hallmark of therapy, the former for fluid overload and the latter for low cardiac output. Recent literature suggests potential drawbacks to these therapies, including neurohormonal activation and a potential worsened survival in patients receiving higher doses of diuretic therapy, and an increased frequency of adverse effects with inotropic therapy. ${ }^{4-10}$

Intravenous furosemide administration has been associated with a reduction in cardiac output, which may result in a reduction in renal blood flow and glomerular filtration rate. ${ }^{4-6}$ Subsequently, these hemodynamic and renal effects result in activation of the renin-angiotensin-aldosterone system and the sympathetic nervous system. ${ }^{7,8}$ Long-term use of furosemide further activates these neurohormonal systems because of relative reductions in intravascular volume. Theoretically, further activation of these negative compensatory systems in heart failure may result in worse clinical outcomes. A retrospective analysis of the Prospective
Randomized Amlodipine Survival Evaluation (PRAISE) trial data suggested that long-term use of diuretics can be harmful. ${ }^{9}$ High diuretic doses were independently associated with total mortality, sudden death, and pump failure death ( $<<0.05$ for all), and the use of metolazone was an independent predictor of total mortality $(\mathrm{p}=0.16)$.

For many years, inotropic therapy has been well established to have proarrhythmic potential. In the Outcomes of a Prospective Trial of Intravenous Milrinone for Exacerbations of Chronic Heart Failure (OPTIME-CHF) trial, intravenous milrinone was associated with significantly more arrhythmia and hypotension compared with placebo in patients with ADHF. ${ }^{10}$ More recently, data from the Acute Decompensated Heart Failure National Registry (ADHERE) further support less favorable outcomes, suggesting an increase in mortality with intravenous inotropic therapies (milrinone and dobutamine) compared with vasodilator therapies (nesiritide and nitroglycerin). ${ }^{11}$

\section{Nesiritide Overview}

Nesiritide (Natrecor; Scios, Inc., Fremont, CA) is the recombinant form of human B-type (brain) natriuretic peptide (BNP), and its amino acid sequence is identical to that of endogenous human BNP. The agent is indicated for the intravenous treatment of patients with ADHF who have dyspnea at rest or with minimal 
Table 1. (continued)

\begin{tabular}{lc}
\hline Results & p Value \\
\hline$\downarrow$ PCWP & $<0.001$ \\
& NS \\
Improvement in both groups: & \\
GCS at 6 hrs, 24 hrs, and end of therapy & \\
Clinical symptoms at 6 hrs, 24 hrs, and & \\
$\quad$ end of therapy & $<0.05$ \\
$\downarrow$ PCWP & 0.03 \\
$\downarrow$ dyspnea & \\
& \\
$\uparrow$ with dobutamine & $<0.05$ \\
$\uparrow$ with dobutamine & $<0.05$ \\
$\uparrow$ with dobutamine & $<0.05$ \\
\hline
\end{tabular}

activity, primarily patients with fluid overload. ${ }^{12}$ In this population, nesiritide causes venodilation and natriuresis that results in reduced pulmonary pressure and relieves dyspnea. Nesiritide is distinct compared with other drugs that have diuretic properties in that it also causes arterial vasodilation, which reduces afterload and indirectly increases cardiac output. ${ }^{13}$

Three pivotal clinical trials were responsible for defining the current role of nesiritide in the management of ADHF; these trials are briefly summarized in Table 1. ${ }^{14-16}$ The first of two large, randomized, controlled trials assessing symptomatology - the Nesiritide Study Group (NSG) - compared nesiritide in 432 patients who were hospitalized for ADHF. ${ }^{14}$ The trial was divided into two parts: the first part, known as the NSG efficacy trial (127 patients), used a double-blind, placebo-controlled design of a nesiritide 6-hour infusion at two dosing schemes; the second part, known as the NSG comparative trial (305 patients), compared standard therapy (defined as a single intravenous vasoactive agent routinely used for the short-term management of ADHF) with two nesiritide groups with the same dosing as in the efficacy trial. Among the 102 patients assigned to the standard therapy group, dobutamine was the most common choice of drug therapy (57\%) followed by milrinone (19\%). Thus, $82 \%$ of patients in the standard therapy group were receiving inotropic therapy. The global clinical status and specific symptoms of heart failure were assessed by the physician and the patient at baseline and at 6 hours after treatment in both parts of the trial.

In the second trial, the Vasodilation in the Management of Acute CHF (VMAC) trial, nesiritide was compared with another vasodilator, nitroglycerin, when either therapy was added to standard of care in patients with ADHF and symptoms at rest. ${ }^{15}$ In addition to dyspnea, this trial identified a second primary end point, pulmonary capillary wedge pressure. The third trial, the Prospective Randomized Evaluation of Cardiac Ectopy with Dobutamine or Natrecor Therapy (PRECEDENT) trial, was primarily a safety trial to compare nesiritide with dobutamine with regard to effects on arrhythmias. ${ }^{16}$

\section{Recent Controversial Literature}

Nesiritide's Effect on Renal Function

The initial product information provided by the manufacturer of nesiritide addressed the issue of worsening renal function as an adverse event in the clinical trials conducted until that point. ${ }^{12}$ The product information reported that nesiritide may affect renal function in susceptible individuals. The manufacturer did state that in patients with severe heart failure whose renal function may depend on the activity of the reninangiotensin-aldosterone system, treatment with nesiritide may be associated with azotemia. Also, the package insert stated that starting nesiritide at doses higher than $0.01 \mu \mathrm{g} / \mathrm{kg} / \mathrm{minute}(0.015$ and $0.030 \mu \mathrm{g} / \mathrm{kg} / \mathrm{min}$ ) is associated with an increased rate of elevated serum creatinine levels over baseline values compared with standard therapies.

The effect of BNP intravenous infusions on renal function has been studied in healthy volunteers. ${ }^{17-22}$ Similar studies have been conducted in patients with heart failure. ${ }^{13,23-26}$ In general, the neuroendocrinologic alterations seen after the administration of BNP have included maintenance of or reduction in aldosterone and renin levels. In healthy volunteers, BNP appears to maintain and perhaps even enhance glomerular filtration rate and maintain renal blood flow. It has modest diuretic properties, with increases in urine sodium excretion and urine volume. Although most of these neurohormonal and renal responses are similar in patients with heart failure, one group of authors reported that the effects of BNP in patients with heart failure appear to be attenuated, with less enhancement of sodium excretion, compared with the effects in healthy patients. ${ }^{24}$ The authors demonstrated that the absolute increase in urinary sodium excretion and the absolute decrease in distal fractional reabsorption of sodium (as measured by lithium clearance) with 
BNP were significantly lower in the patients with heart failure. No significant changes were noted in glomerular filtration rate or renal blood flow between the control group and the patients with heart failure. In contrast, another group of authors found an enhanced response in patients with heart failure. ${ }^{25}$ These investigators found that urinary excretion of sodium was higher in the patients with heart failure than in the control subjects.

Among the studies conducted in patients with heart failure, we know of only one that investigated the effect of nesiritide, rather than BNP, on renal function. ${ }^{26}$ In this study, a nesiritide $2-\mu \mathrm{g} / \mathrm{kg}$ bolus followed by a 0.01 $\mu \mathrm{g} / \mathrm{kg} / \mathrm{minute}$ or a placebo infusion was given for 24 hours, and glomerular filtration rate, renal blood flow, urine output, and sodium excretion were assessed in patients with heart failure who had moderate renal insufficiency. Nesiritide did not improve any of these variables in this population at the end of the 24-hour infusion.

Unfortunately, each of these renal response studies varies greatly in enrollment criteria, method used to measure renal response, washout duration before crossover, and management of long-term diuretic therapy, which may explain the discrepancies in outcomes reported.

To gain a better understanding of the effect of nesiritide on renal function, renal data from the VMAC trial 15 were assessed in a post hoc analysis. ${ }^{27}$ The VMAC trial represents approximately one third of all patients who have been studied with nesiritide; thus, this was a reasonable means to address this issue in a heterogeneous population. In 60 patients with renal insufficiency (serum creatinine level $>2.0$ $\mathrm{mg} / \mathrm{dl}$ ), the median change in serum creatinine level from baseline to the last day of treatment with study drug was $-0.2 \mathrm{mg} / \mathrm{dl}$ with nesiritide $0.01 \mu \mathrm{g} / \mathrm{kg} / \mathrm{minute}$ and $-0.1 \mathrm{mg} / \mathrm{dl}$ with nitroglycerin (dosage titrated to effect, $\mathrm{p}=0.03$ ). For 209 patients without renal insufficiency, the median changes in serum creatinine level from baseline to the last treatment day were the same for nesiritide and nitroglycerin, 0 and $0 \mathrm{mg} / \mathrm{dl}$, respectively ( $\mathrm{p}=0.54)$.

A summary of the mean serum creatinine level at various time points for nesiritide-treated patients with and those without renal insufficiency may be found in Table 2. Although these results overall suggest a neutral effect of nesiritide, results of a recent meta-analysis of clinical trial data suggest an increased risk of worsening renal function in patients with
Table 2. Vasodilation in the Management of Acute CHF (VMAC) Trial: Effect of Nesiritide on Serum Creatinine Concentration in Patients with and without Renal Insufficiency $^{27}$

\begin{tabular}{lcc}
\hline & \multicolumn{2}{c}{ Serum Creatinine Concentration (mg/dl) } \\
\cline { 2 - 3 } Time Frame & $\begin{array}{c}\text { Patients without } \\
\text { Renal Insufficiency }\end{array}$ & $\begin{array}{c}\text { Patients with } \\
\text { Renal Insufficiency }\end{array}$ \\
\hline Baseline & $1.2 \pm 0.3$ & $3.0 \pm 1.5$ \\
Day 2 & $1.3 \pm 0.5$ & $2.9 \pm 1.6$ \\
Day 5 & $1.3 \pm 0.4$ & $3.0 \pm 1.6$ \\
\hline
\end{tabular}

Data are mean \pm SD.

Renal insufficiency defined as a serum creatinine level $\geq 2 \mathrm{mg} / \mathrm{dl}$.

ADHF. $^{28}$ This meta-analysis identified trials through United States Food and Drug Administration (FDA) documents released by the Cardiovascular and Renal Drug Advisory Committee, the drug manufacturer, a PubMed search (limited to clinical trials on humans published in English through July 2004), and a manual search of annual meetings of the American Heart Association, American College of Cardiology, and Heart Failure Society of America. Trials were then selected when they fulfilled each of the following characteristics: randomized, double-blind, parallel-group study in patients with ADHF and in which the effect on serum creatinine level was reported. These sources and criteria revealed five studies included in the analysis. In the five studies, 1288 patients were enrolled and randomized, with 1269 patients undergoing assessment of renal function. The definition of worsening renal function was an increase in serum creatinine level of more than $0.5 \mathrm{mg} / \mathrm{dl}$, the only renal function measurement similar among these trials.

Compared with noninotrope-based control therapy (diuretics and other vasodilators), nesiritide increased the risk of worsening renal function at doses of $0.03 \mu \mathrm{g} / \mathrm{kg} / \mathrm{minute}$ or less and $0.015 \mu \mathrm{g} / \mathrm{kg} / \mathrm{minute}$ or less (22\% vs $15 \%$, $\mathrm{p}=0.003$, and $23 \%$ vs $15 \%, \mathrm{p}=0.012$, respectively) or at any dose $(\leq 0.06 \mu \mathrm{g} / \mathrm{kg} / \mathrm{min}, 22 \%$ vs $15 \%$, $\mathrm{p}=0.002)$. Compared with any control therapy (noninotrope- and inotrope-based therapies), nesiritide increased the risk of worsening renal function at doses of $0.03 \mu \mathrm{g} / \mathrm{kg} / \mathrm{minute}$ or less and $0.015 \mu \mathrm{g} / \mathrm{kg} / \mathrm{minute}$ or less ( $21 \%$ vs $15 \%$, $\mathrm{p}=0.001$, and $21 \%$ vs $15 \%, \mathrm{p}=0.006$, respectively) or at any dose $(\leq 0.06 \mu \mathrm{g} / \mathrm{kg} / \mathrm{min}, 21 \%$ vs $15 \%$, $\mathrm{p}=0.001$ ). In further analysis, nesiritide increased the need for medical intervention compared with control ( $11.1 \%$ vs $4.2 \%, \mathrm{p}=0.03$ ). However, no significant difference was noted between the nesiritide and control groups in the 
Table 3. Vasodilation in the Management of Acute CHF (VMAC) Trial: Temporal Characteristics of Serum Creatinine Concentration Elevations with Nesiritide and Nitroglycerin ${ }^{29}$

\begin{tabular}{lccc}
\hline & \multicolumn{2}{c}{$\begin{array}{c}\text { Percentage of Patients with Serum Creatinine } \\
\text { Concentration Increases }>0.5 \mathrm{mg} / \mathrm{dl}\end{array}$} \\
\cline { 2 - 3 } \multicolumn{1}{c}{$\begin{array}{c}\text { Nitroglycerin } \\
\text { Group } \\
\text { Time Frame }\end{array}$} & $\begin{array}{c}\text { Nesiritide } \\
\text { group } \\
(\mathrm{n}=212)\end{array}$ & 14 & \\
\hline At any time & 12 & 1.5 & $\mathrm{p}$ Value \\
During infusion & 1.9 & 6.7 & 0.50 \\
$<72$ hrs after infusion discontinued & 5.2 & 6.0 & 0.57 \\
$\geq 72$ hrs after infusion discontinued & 4.7 & & 0.69 \\
\hline
\end{tabular}

need for dialysis ( $2.5 \%$ vs $2.2 \%, p=0.71) .^{28}$

Additional data on the effects of nesiritide dose on renal function were presented at the recent Heart Failure Society of America meeting in 2005, subsequent to the publication of the above meta-analysis. Two additional post hoc assessments of the VMAC study data were conducted. Percentages of patients with an increase in serum creatinine level of more than $0.5 \mathrm{mg} / \mathrm{dl}$ at various time points are represented in Table 3 . In this patient subgroup, most increases in serum creatinine level occurred well after discontinuation of study drug. ${ }^{29}$ Another evaluation suggested that the risk of serum creatinine level increases of more than $0.5 \mathrm{mg} / \mathrm{dl}$ was not affected by vasodilator type (nesiritide vs nitroglycerin) in patients who received low-to moderate doses of diuretics (20.2\% nesiritide, $21 \%$ nitroglycerin, $\mathrm{p}=0.975$ ) but was significantly increased in patients who received high-dose diuretics plus nesiritide (32.9\% nesiritide, $21.4 \%$ nitroglycerin, $\mathrm{p}=0.044) .{ }^{30}$ Having assessed patients receiving different doses of nesiritide in five clinical trials (1222 patients), a third abstract reported that the manufacturer-recommended starting dosage of nesiritide, $0.01 \mu \mathrm{g} / \mathrm{kg} / \mathrm{minute}$, did not worsen renal function compared with control $(\mathrm{p}=0.17){ }^{31}$ In contrast, higher starting doses did worsen renal function when compared with controls $(0.015 \mu \mathrm{g} / \mathrm{kg} / \mathrm{min}, \mathrm{p}=0.02$, and $0.03 \mu \mathrm{g} / \mathrm{kg} / \mathrm{min}$, $\mathrm{p}=0.001$ ) in a dose-dependent fashion (Table 4). The risk of increase in serum creatinine level paralleled the rate of symptomatic hypotension; however, it is unknown if this represents a causal relationship.

\section{Nesiritide's Effect on Mortality}

No trial has prospectively identified mortality as a primary end point with nesiritide. Pooled data from the manufacturer in the original product information states that in all controlled
Table 4. Pooled Analysis from Five Trials of Patients Treated with Nesiritide Who Had Increases in Serum Creatinine Concentrations Greater Than $0.5 \mathrm{mg} / \mathrm{dl}$ at Any Time Through Day $30^{31}$

\begin{tabular}{lcl}
\hline $\begin{array}{l}\text { Initial Dosage } \\
(\mu \mathrm{g} / \mathrm{kg} / \mathrm{min})\end{array}$ & Odds Ratio $(95 \% \mathrm{CI})$ & $\mathrm{p}$ Value \\
\hline 0.01 & $1.35(0.88-2.06)$ & 0.17 \\
0.015 & $1.90(1.02-3.54)$ & 0.02 \\
0.03 & $2.58(1.40-4.74)$ & 0.001 \\
\hline $\mathrm{CI}=$ confidence interval.
\end{tabular}

trials combined, the 6-month mortality rates for nesiritide and active control (including nitroglycerin, dobutamine, nitroprusside, milrinone, amrinone, and dopamine) were $21.5 \%$ and $21.7 \%$, respectively. ${ }^{12}$

A recently published meta-analysis, written by the same authors as the above meta-analysis ${ }^{28}$ on nesiritide effects on renal function, brought the issue of nesiritide's effect on mortality to the forefront. ${ }^{32}$ The hypothesis was that if nesiritide worsens renal function, then it may affect mortality. This meta-analysis identified trials through the same mechanism as the abovedescribed meta-analysis that assessed renal function. Trials were then selected when they fulfilled each of the following characteristics: randomized, double-blind, parallel group study of patients with ADHF, nesiritide therapy administered as a single infusion for at least 6 hours, control therapy did not mandate the use of positive inotrope therapy, and mortality was reported during 30 days of follow-up. Twelve randomized controlled trials were identified. Of these 12 , three were excluded because nesiritide was administered as an intravenous bolus. Six trials were excluded because the 30-day mortality rate was not reported, patients without ADHF were enrolled, trial design was open label, inotrope therapy was allowed as a comparator, or intermittent infusion therapy was mandated. 
The three remaining trials (862 patients) were the NSG efficacy trial, VMAC trial, and the Prospective Randomized Outcomes Study of Acutely Decompensated Congestive Heart Failure Treated Initially in Outpatients with Nesiritide (PROACTION) trial. The data on death rates were provided either by the FDA review documents (NSG efficacy trial and VMAC) or by the trial sponsor (PROACTION). The crude mortality rates in the nesiritide and the control groups were $7.2 \%$ and $4.0 \%$, respectively. The meta-analysis using a fixed-effects model revealed no statistically significant difference in risk of death in the nesiritide groups compared with the control groups (risk ratio 1.74, 95\% confidence interval [CI] 0.97-3.12, p=0.059). The adjusted Kaplan-Meier curves of 30-day mortality showed a similar outcome (hazard ratio [HR] $1.80,95 \%$ CI $0.98-3.31, p=0.057)$. The authors concluded that nesiritide may possess an increased risk of mortality compared with noninotrope control groups.

Since this analysis, two other pieces of data have become available with respect to nesiritide's effect on mortality. The ADHERE mortality data were briefly discussed earlier in this review. ${ }^{11}$ The ADHERE is a multicenter, observational, open-label, industry-sponsored registry of the management of patients with ADHF treated in hospitals in the United States. The registry allows any patient given a discharge diagnosis of heart failure from participating acute care centers to be included unless heart failure is not the principal diagnosis or treatment during the admission or if the medical record cannot be accessed for administrative reasons. The first 65,180 patients (October 2001-July 2003) in the registry from 263 hospitals were reviewed, with 15,230 patients included in this analysis. In this database, the in-hospital mortality was compared for all patients who received intravenous treatment with nitroglycerin, nesiritide, milrinone, or dobutamine. Adjustments in the statistical analysis were made to account for eight parameters that are predictors of heart failure inhospital mortality (age, systolic and diastolic blood pressure, blood urea nitrogen level, serum creatinine level, sodium level, heart rate, and dyspnea) along with sex and a propensity score, which was used to produce unbiased estimates of the treatment effect in observational studies. Patients receiving dobutamine and those receiving milrinone had higher in-hospital mortality rates compared with either nitroglycerin- or nesiritide-treated patients $(\mathrm{p}<0.005$;
Table 5. Acute Decompensated Heart Failure National Registry (ADHERE): Nesiritide versus Nitroglycerin and Inotrope Mortality Data ${ }^{11}$

\begin{tabular}{lcc}
\hline $\begin{array}{l}\text { Pair-Wise } \\
\text { Treatment Comparisons }\end{array}$ & Odds Ratio $^{\mathrm{a}}$ & $95 \% \mathrm{CI}$ \\
\hline Nitroglycerin vs milrinone & 0.69 & $0.53-0.89$ \\
Nitroglycerin vs dobutamine & 0.46 & $0.37-0.57$ \\
Nesiritide vs milrinone & 0.59 & $0.48-0.73$ \\
Nesiritide vs dobutamine & 0.47 & $0.39-0.56$ \\
Nesiritide vs nitroglycerin & 0.94 & $0.77-1.16$ \\
Dobutamine vs milrinone & 1.24 & $1.03-1.55$ \\
\hline CI $=$ confidence interval. & & \\
${ }^{a}$ Adjusted for covariates and propensity score.
\end{tabular}

Table 5). No significant difference was noted in in-hospital mortality when comparing nitroglycerin- with nesiritide-treated patients $(\mathrm{p}=0.58)$, but patients receiving dobutamine had a higher in-hospital mortality rate compared with milrinone-treated patients ( $\mathrm{p}=0.027)$.

Having recently updated the package labeling, the manufacturer of nesiritide released 30-day mortality data that was collected in all controlled trials. $^{33}$ These data were made available publicly in the April 2005 update of nesiritide's product information. From these seven trials, the 30-day pooled mortality rate was $5.3 \%$ in the nesiritide group and $4.3 \%$ in the control group (HR 1.27, 95\% CI 0.81-2.01). One of the controlled trials was the Follow-up Serial Infusion of Nesiritide (FUSION I) pilot trial, ${ }^{34}$ an outpatient study with serial nesiritide infusions; this trial was removed to result in a 30-day mortality rate in the nesiritide group versus the control group of $5.9 \%$ and $4.4 \%$, respectively (HR $1.34,95 \% \mathrm{CI}$ 0.84-2.15; Table 6). Four of these studies collected 180-day mortality data. The pooled data from these four trials suggest that the nesiritide group and control group had a 180-day mortality rate of $21.7 \%$ and $21.5 \%$, respectively (HR 1.05, 95\% CI 0.81-1.36; Table 7).

\section{Evolving Literature}

\section{Outpatient Setting}

The FUSION I trial was a pilot study designed to assess safety and tolerability of nesiritide in the outpatient setting. ${ }^{34}$ Patients with New York Heart Association (NYHA) functional class III or IV for at least 60 days before randomization, a 6 minute walk test less than 400 meters, and at least two hospital admissions for ADHF (or an unscheduled outpatient visit requiring therapy with vasoactive drug) within the past 12 months were enrolled. At least one of the hospital 
Table 6. All Nesiritide Controlled Trials with 30-Day Mortality Data ${ }^{33}$

\begin{tabular}{lrrr}
\hline \multirow{2}{*}{ Trial } & \multicolumn{2}{c}{ No. (\%) of Patients } & Hazard Ratio \\
\cline { 2 - 3 } & Nesiritide Group & Control Group & \\
\hline Mills et al & $2 / 74(2.7)$ & $2 / 29(7.5)$ & $0.38(0.05-2.67)$ \\
NSG efficacy & $5 / 85(5.9)$ & $2 / 42(4.8)$ & $1.25(0.24-6.45)$ \\
NSG comparative & $14 / 203(6.9)$ & $5 / 102(4.9)$ & $1.43(0.52-3.97)$ \\
PRECEDENT & $6 / 163(3.7)$ & $5 / 83(6.1)$ & $0.6(0.18-1.97)$ \\
VMAC & $22 / 273(8.1)$ & $11 / 216(5.1)$ & $1.56(0.75-3.24)$ \\
PROACTION & $5 / 120(4.2)$ & $1 / 117(0.9)$ & $4.99(0.58-42.73)$ \\
FUSION I & $2 / 141(1.4)$ & $2 / 69(2.9)$ & $0.49(0.07-3.47)$ \\
Pooled (6 studies) & $54 / 918(5.9)$ & $26 / 589(4.4)$ & $1.34(0.84-2.15)$ \\
Pooled (7 studies) & $56 / 1059(5.3)$ & $28 / 658(4.3)$ & $1.27(0.81-2.01)$ \\
\hline
\end{tabular}

$\mathrm{CI}=$ confidence interval; NSG = Nesiritide Study Group; PRECEDENT $=$ Prospective Randomized Evaluation of Cardiac Ectopy with Dobutamine or Natrecor Therapy; VMAC = Vasodilation in the Management of Acute CHF; PROACTION = Prospective Randomized Outcomes Study of Acutely Decompensated Heart Failure Treated Initially as Outpatients with Nesiritide; FUSION = Follow-up Serial Infusion of Nesiritide.

${ }^{a}$ Data without FUSION I trial.

Table 7. All Nesiritide Controlled Trials with 180-day Mortality Data ${ }^{33}$

\begin{tabular}{lccc}
\hline \multirow{2}{*}{ Trial } & \multicolumn{2}{c}{ No. (\%) of Patients } & Hazard Ratio \\
\cline { 2 - 3 } & NSGiritide Group & Control Group & $(95 \%$ CI) \\
\hline NSG comparative & $19 / 85(23.1)$ & $8 / 42(19.3)$ & $1.25(0.55-2.85)$ \\
PRECEDENT & $42 / 203(20.8)$ & $24 / 102(23.5)$ & $0.88(0.53-1.45)$ \\
VMAC & $26 / 163(16.3)$ & $18 / 83(22.2)$ & $0.74(0.40-1.34)$ \\
Four studies pooled & $67 / 273(25.1)$ & $44 / 216(20.8)$ & $1.22(0.83-1.79)$ \\
\hline CI = confidence interval; NSG = Nesiritide Study Group; PRECEDENT = Prospective Randomized Evaluation of \\
Cardiac Ectopy with Dobutamine or Natrecor Therapy; VMAC = Vasodilation in the Management of Acute CHF.
\end{tabular}

admissions or unscheduled visits should have occurred within 5-30 days of enrollment. After an intravenous bolus, two nesiritide doses, 0.005 $\mu \mathrm{g} / \mathrm{kg} / \mathrm{minute}$ (72 patients) and $0.01 \mu \mathrm{g} / \mathrm{kg} /$ minute (69 patients) for 4-6 hours, were compared with standard care (69 patients). Although inotropic therapy was not allowed in the nesiritide treatment groups, inotropes were permitted in the standard care group. Nesiritide frequency was determined by the primary investigator but was a minimum of every other week and a maximum of twice/week. Duration of therapy was 12 weeks, and the study assessed safety and tolerability through investigator reporting of adverse events and study drug discontinuation due to adverse events. Nesiritide was administered on 1645 occasions, and 11 discontinuations (< $1 \%)$ due to adverse events occurred. No increase in the frequency of adverse events occurred in either the nesiritide or the standard care group. Nesiritide was discontinued in four patients (6\%) receiving $0.005 \mu \mathrm{g} / \mathrm{kg} / \mathrm{minute}$ and five patients (7\%) receiving $0.01 \mu \mathrm{g} / \mathrm{kg} /$ minute. Several secondary clinical end points were assessed (Table 8). No significant difference was noted in death (7/69 [10\%] vs 9/141 [6\%], $\mathrm{p}=0.314)$ or all-cause hospitalization $(37 / 69$ [54\%] vs 65/141 [46\%], $p=0.378$ ) in the standard care group versus the combined nesiritide groups. There was a trend toward an increase in days alive and out of the hospital in nesiritidetreated patients. The investigators concluded that outpatient administration was safe and that additional studies were necessary to determine effect on morbidity and mortality in the outpatient setting. The greatest limitation of this trial was that inotropic therapy was allowed in the standard care group, specifically 40 patients (58\%) in the standard care group received intravenous inotropic therapy. Without a placebo control group, only conclusions with respect to nesiritide compared with inotrope can be made.

The FUSION II trial was designed to further assess the safety and efficacy of serial infusions of outpatient nesiritide. ${ }^{35}$ Two dosing frequencies will be assessed, once/week and twice/week, in this placebo-controlled trial. Patients will be treated for 3 months and, in a blinded follow-up 
Table 8. Follow-up Serial Infusion of Nesiritide (FUSION) I Trial ${ }^{34}$

\begin{tabular}{|c|c|c|c|c|}
\hline $\begin{array}{l}\text { Safety and Other } \\
\text { Clinical Outcomes }\end{array}$ & $\begin{array}{c}\text { Standard Care } \\
(n=69)\end{array}$ & $\begin{array}{c}\text { Nesiritide } \\
0.005 \mu \mathrm{g} / \mathrm{kg} / \mathrm{min} \\
(\mathrm{n}=72)\end{array}$ & $\begin{array}{c}\text { Nesiritide } \\
0.01 \mu \mathrm{g} / \mathrm{kg} / \mathrm{min} \\
(\mathrm{n}=69) \\
\end{array}$ & $\begin{array}{c}\text { All } \\
\text { Nesiritide } \\
(\mathrm{n}=141)\end{array}$ \\
\hline & \multicolumn{4}{|c|}{ No. (\%) of Patients } \\
\hline $\begin{array}{l}\text { Primary end point } \\
\text { Infusion terminated due } \\
\text { to adverse events }\end{array}$ & NA & $4(6)$ & $5(7)$ & $9(6)$ \\
\hline $\begin{array}{l}\text { Secondary end points } \\
\text { Death } \\
\text { All-cause hospitalization }\end{array}$ & $\begin{array}{r}7(10) \\
37(54) \\
\end{array}$ & $\begin{array}{c}6(8), p=0.692 \\
32(44), p=0.314\end{array}$ & $\begin{array}{c}3(4), p=0.194 \\
33(48), p=0.610\end{array}$ & $\begin{array}{c}9(6), \mathrm{p}=0.314 \\
65(46), \mathrm{p}=0.378\end{array}$ \\
\hline \multicolumn{5}{|c|}{ Mean \pm SD } \\
\hline Days alive and out of hospital & $74 \pm 18$ & $76 \pm 15, p=0.253$ & $79 \pm 11, p=0.159$ & $78 \pm 13, p=0.131$ \\
\hline
\end{tabular}

period, will be followed for an additional 3 months. Standard care will be allowed in all treatment arms. It is anticipated that 300 patients will be randomly assigned to each of the two nesiritide arms and 150 patients will be enrolled to each of the two placebo arms. For efficacy, a combined end point of mortality and cardiorenal rehospitalization will be assessed. Patient enrollment is complete.

\section{Emergency Department or Observational Unit}

The PROACTION Trial was a pilot study to assess the safety and efficacy of nesiritide in patients with ADHF who were being managed in the emergency department. ${ }^{36}$ This multicenter, double-blind, placebo-controlled study enrolled patients who came to the emergency department with ADHF, defined as heart failure causing dyspnea at rest or with minimal activity and requiring intravenous therapy for at least 12 hours. Patients received a nesiritide $2-\mu \mathrm{g} / \mathrm{kg}$ bolus followed by a $0.01-\mu \mathrm{g} / \mathrm{kg} / \mathrm{minute}$ or placebo infusion for at least 12 hours. Patients were allowed to receive standard care with the following exceptions: oral angiotensinconverting enzyme (ACE) inhibitors were not allowed from 2 hours before until 30 minutes after start of study drug, and intravenous dopamine, dobutamine, milrinone, $\beta$-blockers, ACE inhibitors, nitroglycerin, and nitroprusside were not allowed from 2 hours before until 3 hours after start of study drug. Patients were not enrolled if it was anticipated that they could not be discharged from the emergency department or observation unit in less than 24 hours. This study reported the effect of nesiritide on systolic and diastolic blood pressure, heart rate, and occurrence of hypotension. Among the 237 patients enrolled (120 in the nesiritide group, 117 in the placebo group), no significant differences were noted in baseline characteristics or concomitant drug administration during the 12-hour treatment phase between the two treatment groups.

Only $60 \%$ of patients enrolled were NYHA class III or IV, and only $6 \%$ had systolic blood pressures below $101 \mathrm{~mm} \mathrm{Hg}$, suggesting a population with less severe heart failure. During the 12-hour treatment phase, no significant difference was noted in overall blood pressure between the two treatment groups. At 6 hours, nesiritide significantly reduced both systolic (by 13 vs $4 \mathrm{~mm} \mathrm{Hg}, \mathrm{p}<0.001$ ) and diastolic (by 6 vs 0 $\mathrm{mm} \mathrm{Hg}, \mathrm{p}=0.002$ ) blood pressure, compared with placebo. At 12 hours, nesiritide significantly reduced both systolic (by 17 vs $6 \mathrm{~mm} \mathrm{Hg}$, $\mathrm{p}<0.001$ ) and diastolic (by 7 vs $1 \mathrm{~mm} \mathrm{Hg}$, $\mathrm{p}=0.003$ ) blood pressure compared with placebo. The reduction in systolic blood pressure with nesiritide was proportional to baseline systolic blood pressure. Heart rate was slightly reduced in both treatment groups, with no significant differences except at 6 hours (4.1 vs -0.8 beats/min nesiritide vs placebo, $\mathrm{p}=0.029)$. There were no significant differences in the rate of symptomatic or asymptomatic hypotension between the two groups. Complaints of headache or leg cramps were also similar between the two treatment groups. The authors concluded that nesiritide was safe and effective at reducing blood pressure, which may serve as a reasonable surrogate for afterload reduction in the absence of invasive hemodynamics. 
From these same investigators, an abstract with additional outcome data was presented at the American College of Cardiology meeting in Spring 2003. ${ }^{37}$ The investigators refer to 250 patients with decompensated heart failure who were randomly assigned to receive nesiritide or placebo for at least 12 hours. From the emergency department, nesiritide-treated patients were less likely to be admitted (49\% vs 55\%) and less likely to be admitted for heart failure (30\% vs $38 \%$ ) than those in the placebo group (no p value reported). Of the patients who did require hospitalization, nesiritide-treated patients had a lower 30 -day rehospitalization rate ( $10 \%$ vs $23 \%$, $\mathrm{p}=0.058$ ) and a lower 30-day length of stay (includes initial visit and rehospitalization, 5.5 vs 10.2 days, $\mathrm{p}=0.052$ ) than the placebo group. The overall cost was lower in patients treated with nesiritide, primarily due to a reduction in length of stay and rehospitalization. The authors did not include these results in the above publication of this study ${ }^{36}$ nor have they published these results separately.

Most recently, in January 2006, the manufacturer of nesiritide reported two additional deaths of patients who were enrolled in the PROACTION study. ${ }^{35}$ These deaths occurred within 30 days after treatment with nesiritide and were not previously reported in the original PROACTION trial report to the FDA. Inclusion of these deaths into the overall number of deaths that have occurred with nesiritide compared with control would be a mortality rate of $5.5 \%$ and $4.3 \%$, respectively. Since PROACTION was included in the mortality meta-analysis, how these two additional deaths would influence the 30-day mortality results is unknown.

An analysis of ADHERE data assessed the effect of beginning vasoactive therapy in the emergency department on outcomes. ${ }^{38}$ At the time of analysis, ADHERE contained data from 265 acute care hospitals. The investigators assessed patients admitted through the emergency department between October 2001 and July 2003 who had received nesiritide but no other intravenous vasoactive drug. Patients who received nesiritide in the emergency department (803 patients) were compared with those who received nesiritide after admission (1223 patients). Median time to start of nesiritide therapy was shorter in patients treated in the emergency department (2.7 vs $18.3 \mathrm{hrs}, \mathrm{p}<0.0001)$ and median length of stay was also reduced (4.1 vs 5.7 days, $\mathrm{p}<0.0001$ ) compared with those treated after admission. Patients in whom therapy was delayed were more likely to require transfer to the intensive care unit and to have a prolonged length of stay ( $9 \%$ vs $2 \%$ and $35 \%$ vs $19 \%$, $\mathrm{p}<0.0001)$. The authors concluded that early start of nesiritide resulted in better patient outcomes. Study results have been published only as an abstract at this time.

\section{Reducing Length of Stay and Cost}

One group of authors retrospectively assessed the data of 129 consecutive admissions to the coronary care unit in 98 patients with a diagnosis of heart failure. ${ }^{39}$ Patients receiving nesiritide (58 patients) were compared with patients who did not receive nesiritide (71 patients). Overall, the nesiritide-treated patients appeared to have more severe heart failure with a lower baseline ejection fraction and systolic blood pressure, a higher serum creatinine level, and longer QRS duration. Despite this suggestion of an increased severity of illness and no significant change in weight or renal function, nesiritide-treated patients had a significantly shorter length of stay $(\mathrm{p}=0.002$; Table 9) compared with those not receiving nesiritide, and multiple linear regression analysis indicated that length of stay was significantly related to nesiritide use $(p=0.001)$. The authors concluded that nesiritide may facilitate early discharge of patients without harming renal function. Data from ADHERE have demonstrated that lower systolic blood pressure and a higher blood urea nitrogen and serum creatinine level on presentation to the hospital are indeed associated with an increase in mortality, so the conclusion by authors that nesiritide-treated patients had greater severity of disease seems reasonable. ${ }^{40}$ However, given the retrospective nature of this study design, the lack of other important baseline differences between the two treatment groups cannot be established and differences in patient management with other ADHF therapies cannot be determined as not having influenced the study outcome.

Results of the NSG trial and the PRECEDENT trial are described in Table 1. One group of authors retrospectively combined the data for nesiritide- and dobutamine-treated patients from the NSG comparative and PRECEDENT trials to assess nesiritide's effects on length of treatment and length of stay as well as mortality. ${ }^{41}$ No significant differences were noted in the baseline characteristics or hemodynamics between treatment groups with the exception of the following: history of myocardial infarction and 
Table 9. Retrospective Assessment of Nesiritide's Effect on Length of Stay ${ }^{39}$

\begin{tabular}{lccc}
\hline & $\begin{array}{c}\text { Patients } \\
\text { Receiving } \\
\text { Nesiritide } \\
(\mathrm{n}=58)\end{array}$ & $\begin{array}{c}\text { Patients } \\
\text { Not Receiving } \\
\text { Nesiritide } \\
(\mathrm{n}=72)\end{array}$ & $\mathrm{p}$ Value \\
\hline Assessment & & & \\
\hline Baseline parameters & $116 \pm 23$ & $129 \pm 29$ & 0.0126 \\
$\quad$ Systolic blood pressure (mm Hg) & $20 \pm 14$ & $32 \pm 24$ & 0.0156 \\
Ejection fraction (\%) & $150 \pm 42$ & $128 \pm 39$ & 0.0084 \\
QRS duration (msec) & $136 \pm 5$ & $137 \pm 6$ & 0.3375 \\
Sodium level (mEq/L) & $44 \pm 30$ & $37 \pm 24$ & 0.1897 \\
Blood urea nitrogen level (mg/dl) & $1.80 \pm 0.87$ & $1.52 \pm 0.89$ & 0.1163 \\
Serum creatinine level (mg/dl) & & & \\
Outcomes from admission to discharge & $-1.9 \pm 13.3$ & $-1.3 \pm 13.5$ & 0.8043 \\
$\quad$ Change in blood urea nitrogen level (mg/dl) & $-0.11 \pm 0.55$ & $-0.07 \pm 0.38$ & 0.6348 \\
Change in serum creatinine level (mg/dl) & $-2.83 \pm 1.91$ & $-2.33 \pm 2.22$ & 0.1981 \\
Change in weight (lbs/day) & $3.91 \pm 1.3$ & $4.77 \pm 1.7$ & 0.0023 \\
$\quad$ Length of stay (days) & & &
\end{tabular}

ischemia as causes of heart failure was greater in the dobutamine group, whereas fewer patients receiving nesiritide $0.015 \mu \mathrm{g} / \mathrm{kg} /$ minute were white or had a history of sudden death and more patients receiving nesiritide $0.03 \mu \mathrm{g} / \mathrm{kg} /$ minute had a history of sustained ventricular tachycardia. The investigators reported a shorter total duration of administration $(\mathrm{p}<0.001)$ and shorter total duration of all intravenous vasoactive therapy $(\mathrm{p} \leq 0.012)$ with nesiritide $0.015 \mu \mathrm{g} / \mathrm{kg} /$ minute as well as nesiritide $0.03 \mu \mathrm{g} / \mathrm{kg} /$ minute compared with dobutamine. Although no significant difference was noted in median length of stay between the nesiritide- and dobutaminetreated patients, a trend existed for fewer allcause readmissions at 21 days with both nesiritide groups ( $8 \%$ nesiritide $0.015 \mu \mathrm{g} / \mathrm{kg} / \mathrm{min}$ and $11 \%$ nesiritide $0.03 \mu \mathrm{g} / \mathrm{kg} / \mathrm{min}$ vs $20 \%$ dobutamine, overall $\mathrm{p}<0.05$, low-dose nesiritide $\mathrm{p}=0.085)$ and a significantly lower mortality at 6 months in the lower dose nesiritide group (18\% nesiritide $0.015 \mu \mathrm{g} / \mathrm{kg} / \mathrm{min}$ and $24 \%$ nesiritide $0.03 \mu \mathrm{g} / \mathrm{kg} / \mathrm{min}$ vs $31 \%$ dobutamine, overall $\mathrm{p}<0.05$, low-dose nesiritide $\mathrm{p}=0.123$ ). The primary limitation of this study was the retrospective nature of the assessment as well as the comparison with dobutamine rather than placebo. The possibility that confounding by indication did not occur with dobutamine-treated patients having more severe underlying disease cannot be eliminated.

Both of the above retrospective studies can be compared with that of the VMAC trial in which nesiritide-treated patients had a longer length of stay ( 10 vs 8 days, $p=0.08$ ) compared with nitroglycerin-treated patients. ${ }^{35}$
Another group of authors combined the results of the NSG comparative trial and PRECEDENT trial to study the economic implications of nesiritide compared with dobutamine. ${ }^{42}$ Cost of medical care was determined by the Monte Carlo simulation to estimate treatment cost and survival in hypothetical cohorts (1000 patients/treatment group) since neither trial recorded charges or resource utilization. Only events that were both clinically significant and likely to generate use of additional medical resources were identified. For example, symptomatic hypotension was included, whereas asymptomatic hypotension was not. Of importance, patients receiving nesiritide $0.03 \mu \mathrm{g} / \mathrm{kg} / \mathrm{minute}$ were excluded. The simulation suggested that despite a higher acquisition cost, nesiritide was associated with less resource utilization during the initial hospital stay as well as a lower readmission rate at 21 days, which resulted in a cost neutral end result (Table 10). The authors also suggested a survival advantage. The primary limitation of this study was the comparison with dobutamine rather than placebo. It is important to mention again that all patients receiving nesiritide $0.03 \mu \mathrm{g} / \mathrm{kg} /$ minute were excluded from the simulation, which could have influenced the outcome of the study given that higher nesiritide doses are associated with greater adverse effects. In addition, this economic evaluation did not account for selection bias with dobutamine-treated patients and uncertainty in 21-day heart failure readmission and 6-month mortality estimates.

Given the limitations of the above economic evaluation, ${ }^{42}$ another group performed an economic analysis of the only randomized 
Table 10. Economic Comparison of Nesiritide versus Dobutamine $e^{42}$

\begin{tabular}{|c|c|c|c|}
\hline Variable & $\begin{array}{l}\text { Nesiritide } \\
\text { Group }\end{array}$ & $\begin{array}{c}\text { Dobutamine } \\
\text { Group }\end{array}$ & \\
\hline \multicolumn{4}{|c|}{ Percentage of Patients } \\
\hline Clinical event & $(n=188)$ & $(n=144)$ & $\mathrm{p}$ Value \\
\hline Cardiac arrest & 2.7 & 3.6 & 0.746 \\
\hline Symptomatic hypotension & 17.1 & 5.7 & 0.000 \\
\hline Readmission for heart failure & 4 & 9.4 & 0.030 \\
\hline 6-mo mortality & 16 & 25 & 0.030 \\
\hline \multicolumn{4}{|c|}{ Mean \pm SE } \\
\hline Cost model result & $(n=1000)$ & $(n=1000)$ & Difference $^{a}$ \\
\hline \multicolumn{4}{|l|}{ Cost at initial admission } \\
\hline Without study drug cost & $\$ 10,969 \pm 72$ & $\$ 11,091 \pm 80$ & $\$-122 \pm 91$ \\
\hline With study drug cost & $\$ 11,729 \pm 72$ & $\$ 11,127 \pm 80$ & $\$ 602 \pm 91$ \\
\hline $\begin{array}{l}\text { Cost of readmission for heart } \\
\text { failure } \\
\text { Cost of treatment episode } \mathrm{e}^{\mathrm{b}}\end{array}$ & $\begin{array}{r}\$ 345 \pm 57 \\
\$ 12,074 \pm 93\end{array}$ & $\begin{array}{c}\$ 1029 \pm 99 \\
\$ 12,156 \pm 129\end{array}$ & $\begin{aligned} \$-686 & \pm 114 \\
\$-83 & \pm 145\end{aligned}$ \\
\hline
\end{tabular}

Difference is nesiritide cost minus dobutamine cost.

'Initial admission plus readmission for heart failure.

comparison with dobutamine, the PRECEDENT trial, and these authors used multiple methods of probabilistic sensitivity analysis. ${ }^{43}$ Monte Carlo analysis was used to create results for three scenarios: best-case nesiritide, best-case dobutamine, and a full probabilistic analysis. The two best-case analyses took into consideration 95\% CIs for 21-day heart failure readmission and 6-month mortality. In addition, the analysis performed by the previously mentioned group ${ }^{42}$ was reproduced. When the uncertainty around point estimates for readmission and mortality were included, either nesiritide or dobutamine could be proved as the dominant therapy (greater efficacy with lower cost). Overall, these investigators found that nesiritide did not provide robust economic benefit over dobutamine. The investigators did acknowledge the limitations of their study design. More important, they appropriately questioned the comparison of nesiritide with dobutamine given that the two therapies are routinely used in different heart failure subpopulations.

More recently, a retrospective cohort study analyzed the outcomes associated with vasoactive therapy in ADHF. ${ }^{44}$ The authors reviewed information from the University HealthSystem Consortium clinical database, which contains data from 32 academic institutions, and categorized patients according to the vasoactive therapy received. Length of stay, total health care costs, and in-hospital mortality rate were assessed. In-hospital and intensive care unit mean length of stay were significantly shorter in nesiritide-treated patients ( 7.0 and 1.1 days, respectively) compared with both milrinone (12.2 and 3.9 days, respectively) and dobutamine (10.4 and 3.5 days, respectively) ( $<<0.001$ for all comparisons). Mean total health care costs were lower in nesiritide-treated patients $(\$ 18,517)$ compared with milrinone $(\$ 29,507 ; \mathrm{p}<0.001)$, but not significantly lower than dobutamine $(\$ 23,116)$. The in-hospital mortality rate was significantly higher in the milrinone $(7.9 \%)$ and dobutamine (10.2\%) group compared with the nesiritide group (2.9\%; $<<0.001)$, even after adjustment for baseline variables.

Although this study shows some interesting results, there are some criticisms in the design. ${ }^{44}$ Not only was the study retrospective with a potential selection bias, but the baseline characteristics were not matched optimally. As stated previously, data from the ADHERE registry demonstrated that low systolic blood pressure, and high blood urea nitrogen and serum creatinine levels in patients presenting to the hospital are associated with an increase in inhospital mortality, ${ }^{40}$ but none of these baseline characteristics were reported or controlled for in this analysis. ${ }^{44}$ These data then lead to unclear conclusions of how nesiritide fits into the management of ADHF.

\section{Discussion}

The questions raised by the studies reviewed in this article are thought provoking and generate several research hypotheses that need to be 
Table 11. Ongoing and Future Nesiritide Trials ${ }^{33}$

\begin{tabular}{|c|c|}
\hline Trial & Intent \\
\hline NAPA $(n=250)$ & Evaluation of nesiritide after coronary artery bypass graft \\
\hline FUSION II $(n=900)$ & Outpatient serial infusion of nesiritide in chronic decompensated heart failure (stage C/D) \\
\hline ETNA $(n=1900)$ & Evaluation of nesiritide in acute decompensated heart failure \\
\hline MMAC $(n=3000-5000)$ & Evaluation of nesiritide in acute decompensated heart failure \\
\hline
\end{tabular}

addressed. Unfortunately, the limitations of the design of these studies allow one to question the results, as the data were generated from retrospective observations, meta-analyses, pooled analyses, abstracts, and industry-sponsored registries. Future studies should address the role of nesiritide in reducing hospital length of stay and cost, as well as in preventing hospital admission. Nesiritide's effect on renal function and mortality should be closely examined. In addition, efficacy and safety needs to be assured in various heart failure subpopulations.

The effect of nesiritide on renal function and mortality are critically important as it currently remains unknown if the use of nesiritide in heart failure has the potential for long-term harm or benefit. One could propose that, as with diuretic therapy, reductions in intravascular volume may occur with nesiritide and be responsible for adverse renal effects. Hypotension associated with significant reductions in vascular tone could worsen renal perfusion as well.

Interrelated, the overall response to nesiritide may vary greatly depending on the heart failure subpopulation assessed. For example, patients with volume-dependent low cardiac output are less apt to tolerate large shifts in fluid. Also, patients with low systemic vascular resistance will likely not tolerate significant arterial vasodilation. Perhaps this agent could be more safely and effectively administered to a select subpopulation of patients with heart failure by using more patient-specific dosing recommendations.

In addition, the effect of nesiritide on hospital length of stay and readmission is equally important, as hospitalization is the primary determinant of cost associated with management of heart failure. Despite the high acquisition cost associated with nesiritide, if hospital stay or readmission were reduced significantly with its use, it may be a cost-effective therapy. Without further study, the effect of nesiritide on any of the above end points remains unknown. Several clinical trials with nesiritide are ongoing (Table 11). We hope future clinical trials will address the questions raised by the retrospective studies and meta-analyses and provide a better understanding of the role of nesiritide in the management of ADHF and the various subpopulations within this disease state. Until additional data are available, nesiritide use should be limited to the patient population studied and for the purposes for which it has been demonstrated to be beneficial.

\section{Conclusion}

At this time, the literature supports nesiritide use in patients who come to the hospital with ADHF and dyspnea at rest or with minimal activity for the purpose of rapid symptom control. As suggested in the product labeling, nesiritide should be started at $0.01 \mu \mathrm{g} / \mathrm{kg} / \mathrm{min}$ ute. Nesiritide should be avoided in patients with cardiogenic shock and systolic blood pressure below $90 \mathrm{~mm} \mathrm{Hg}$. Because of dose-related hypotension and renal dysfunction, upward titration of the dosage should be minimized.

Given the significant morbidity and mortality associated with ADHF and the substantial economic impact of this disease, the need for additional therapies and clinical trials supporting these therapies is warranted. Until such studies are conducted, the ADHF population will continue to be managed with the currently available therapies, which are hindered by limited efficacy and adverse effects. Practitioners caring for these patients will remain hopeful that new therapies and supporting literature will be generated in a timely fashion.

\section{References}

1. American Heart Association, American Stroke Association Heart disease and stroke statistics: 2006 update. Dallas, TX: American Heart Association, 2006. Available from http://www.americanheart.org/downloadable/heart/1135358648 
58055-1026_HS_Stats06book.pdf. Accessed March 12, 2006.

2. Chin MH, Golman L. Correlation of major complications or death in patients admitted to the hospital with congestive heart failure. Arch Intern Med 1996;156:1814-20.

3. Adams KF, Lindenfeld J, Arnold JMO, et al. HFSA 2006 comprehensive heart failure guideline. J Card Fail 2006; 12:10-38.

4. Francis GS, Siegel R, Goldsmith SR, et al. Acute vasoconstrictor response to furosemide in patients with chronic congestive heart failure. Ann Intern Med 1985;103:1-6.

5. Fett DL, Cavero PG, Burnett Jr JC. Low-dose atrial natriuretic factor and furosemide in experimental acute congestive heart failure. J Am Soc Nephrol 1993;4:162-7.

6. Ikram H, Chan W, Espiner EA, Nicholls MG. Hemodynamic and hormone response to acute and chronic furosemide therapy in congestive heart failure. Clin Sci 1980;59:443-9.

7. Schaer G, Covit AB, Laragh JH, Cody RJ. Association of hyponatremia with increased renin activity in chronic congestive heart failure: impact on diuretic therapy. Am J Cardiol 1983;51:1635-8

8. Bayliss J, Norell M, Canepa-Anson R, et al. Untreated heart failure: clinical and neuroendocrine effects of introducing diuretics. Br Heart J 1987;57:17-22.

9. Neuberg GW, Miller AB, O'Connor CM, for the PRAISE Investigators. Prospective randomized amlodipine survival evaluation: diuretic resistance predicts mortality in patients with advanced heart failure. Am Heart J 2002;144:31-8.

10. Cuffe MS, Califf RM, Adams Jr KF, et al. Outcomes of a prospective trial of intravenous milrinone for exacerbations of chronic heart failure (OPTIME-CHF) investigators. Short-term intravenous milrinone for acute exacerbation of chronic heart failure: a randomized controlled trial. JAMA 2002;287:1541-7.

11. Abraham WT, Adams KF, Fonarow GC, et al. In-hospital mortality in patients with acute decompensated heart failure requiring intravenous vasoactive medications. J Am Coll Cardiol 2005;46:57-64.

12. Scios, Inc. Natrecor (nesiritide) product labeling. Fremont, CA; 2001.

13. Abraham WT, Lowes BD, Freguson DA, et al. Systemic hemodynamic, neurohormonal, and renal effects of a steadystate infusion of human brain natriuretic peptide in patients with hemodynamically decompensated heart failure. J Card Fail 1998;4:37-44.

14. Colucci WS, Elkayam U, Horton DP, et al, for the Nesiritide Study Group. Intravenous nesiritide, a natriuretic peptide, in the treatment of decompensated congestive heart failure. $\mathrm{N}$ Engl J Med 2000;343:246-53.

15. Publication Committee for the VMAC Investigators. Intravenous nesiritide vs nitroglycerin for the treatment of decompensated congestive heart failure: a randomized controlled trial. JAMA 2002;287:1531-40. (Erratum in JAMA 2002;288:577.)

16. Burger AJ, Horton DP, LeJemtel T, et al. Prospective randomized evaluation of cardiac ectopy with dobutamine or natrecor therapy: effect of nesiritide (B-type natriuretic peptide) and dobutamine on ventricular arrhythmias in the treatment of patients with acutely decompensated congestive heart failure-the PRECEDENT study. Am Heart J 2002;144:1102-8.

17. Van der Zander K, Houben AJ, Hofstra L, et al. Hemodynamic and renal effects of low-dose brain natriuretic peptide infusion in humans: a randomized, placebo-controlled crossover study. Am J Physiol Heart Circ Physiol 2003;285:H1206-12.

18. Holmes SJ, Espiner EA, Richards AM, et al. Renal, endocrine, and hemodynamic effects of human brain natriuretic peptide in normal man. J Clin Endocrinol Metab 1993;76:91-6.

19. LaVilla G, Fronzaroli C, Lazzeri C, et al. Cardiovascular and renal effects of low dose brain natriuretic peptide infusion in man. J Clin Endocrinol Metab 1994;78:1166-71.

20. Jensen KT, Carstens J, Pedersen EB. Effect of BNP on renal hemodynamics, tubular function and vasoactive hormones in humans. Am J Physiol 1998;274:F63-72.

21. McGregor A, Richards M, Espiner E, et al. Brain natriuretic peptide administered to man: actions and metabolism. J Clin
Endocrinol Metab 1990;70:1103-7.

22. Lainchbury JG, Richards AM, Nicholls MG, et al. The effects of pathophysiological increments in brain natriuretic peptide in left ventricular systolic dysfunction. Hypertension 1997;30(3 pt 1):398-404

23. Marcus LS, Hart D, Packer M, et al. Hemodynamic and renal excretory effects of human brain natriuretic peptide infusion in patients with congestive heart failure: a double-blind, placebocontrolled, randomized crossover trial. Circulation 1996;94: 3184-9.

24. Jensen KT, Eishkjeen H, Carstens J, Pedersen E. Renal effects of brain natriuretic peptide in patients with congestive heart failure. Clin Sci 1999;96:5-15.

25. Yoshirmura M, Yasue H, Morita E, et al. Hemodynamic, renal, and hormonal responses to brain natriuretic peptide infusion in patients with congestive heart failure. Circulation 1991;84: 1581-8.

26. Wang DJ, Dowling TC, Meadows D, et al. Nesiritide does not improve renal function in patients with chronic heart failure and worsening serum creatinine. Circulation 2004;110:1620-5.

27. Butler J, Emerman C, Peacock WF, et al, on behalf of the Vasodilation in the Management of Acute Heart Failure (VMAC) Investigators. The efficacy and safety of B-type natriuretic peptide (nesiritide) in patients with renal insufficiency and acutely decompensated heart failure. Nephrol Dial Transplant 2004;19:391-9.

28. Sackner-Bernstein JD, Skopicki H, Aaronson KD. Risk of worsening renal function with nesiritide in patients with acutely decompensated heart failure. Circulation 2005;111: 1487-91.

29. Heywood JT. Temporal characteristics of serum creatinine elevations in patients receiving nesiritide and nitroglycerin [abstr]. J Card Fail 2005;11:S158.

30. Heywood JT. Combining nesiritide with high-dose diuretics may increase the risk of increased serum creatinine [abstr]. J Card Fail 2005;11:S154.

31. Abraham WT. Serum creatinine elevations in patient receiving nesiritide are related to starting dose [abstr]. J Card Fail 2005;11:S156.

32. Sackner-Bernstein JD, Kowalski M, Fox M, Aaronson KD. Short-term risk of death after treatment with nesiritide for decompensated heart failure: A pooled analysis of randomized controlled trials. JAMA 2005; 293:1900-5.

33. Scios, Inc. Natrecor (nesiritide) product labeling. Fremont, CA; 2005.

34. Yancy CW, Saltzberg MT, Berkowitz RL, et al. Safety and feasibility of using serial infusions of nesiritide for heart failure in an outpatient setting: from the follow-up serial infusion of nesiritide (FUSION) I trial. Am J Cardiol 2004;94:595-601.

35. Scios, Inc. Data on file. Fremont, CA; 2005.

36. Peacock WF, Emerman CL, Silver MA, on behalf of the Prospective Randomized Outcomes Study of Acutely Decompensated Heart Failure Treated Initially as Outpatients with Nesiritide (PROACTION) Study Group. Nesiritide added to standard care favorably reduces systolic blood pressure compared with standard care alone in patients with acute decompensated heart failure. Am J Emerg Med 2005;23:327-31.

37. Peacock WF, Emerman CL, on behalf of the Prospective Randomized Outcomes Study of Acutely Decompensated Heart Failure Treated Initially as Outpatients with Nesiritide (PROACTION) Study Group. Safety and efficacy of nesiritide in the treatment of decompensated heart failure in observation patients [abstr]. J Am Coll Cardiol 2003;41:336A.

38. Peacock WF, Emerman CL, Wynne J, on behalf of the Acute Decompensated Heart Failure National Registry (ADHERE) Scientific Advisory Committee and Investigators. Early use of nesiritide in the emergency department is associated with improved outcome: an ADHERE registry analysis [abstr]. Ann Emerg Med 2004:44:S78.

39. Chang R, Elatre WA, Heywood JT. Effect of nesiritide on length of hospital stay in decompensated heart failure. J Cardiovasc Pharmacol Ther 2004;9:173-7. 
40. Fonarow GC, Adams KF, Abraham WT, Yancy CW, Boscardin WJ. Risk stratification for in-hospital mortality in acutely decompensated heart failure: classification and regression tree analysis. JAMA 2005;293:572-80.

41. Silver MA, Horton DP, Ghali JK, Elkayam U. Effect of nesiritide vs dobutamine on short-term outcomes in the treatment of patients with acutely decompensated heart failure. J Am Coll Cardiol 2002;39:798-803.

42. Lissovoy G, Stier DM, Ciesla G, et al. Economic implications of nesiritide vs dobutamine in the treatment of patients with acutely decompensated congestive heart failure. Am J Cardiol 2003;9:631-3.

43. Gerhard T, Zineh I, Winterstein AG, Hartzema AG Pharmacoeconomic modeling of nesiritide versus dobutamine for decompensated heart failure. Pharmacotherapy 2006;26: 34-43.

44. Arnold LM, Crouch MA, Carroll NV, Oinonen MJ. Outcomes associated with vasoactive therapy in patients with acute decompensated heart failure. Pharmacotherapy 2006;26: 1078-85. 